\title{
Therapeutic approaches for deaf children at intervention centers in Chile's metropolitan region: access to health and education
}

Mario Bustos Rubilar ${ }^{(1,2)}$ Eduardo Fuentes-López ${ }^{(3,4)}$

Patricia Castro Abarca(2) $^{(2)}$

(1) Instituto de la Sordera, Santiago, Chile

(2) Facultad de Medicina, Universidad de Chile, Santiago, Chile.

(3) Escuela de Salud Pública, Universidad de Chile, Santiago, Chile.

(4) Facultad de Medicina, Pontificia Universidad Católica de Chile, Santiago, Chile.

Research done at the Departamento de Fonoaudiología of Universidad de Chile along with the Departamento de Ciencias de la Salud, Carrera de Fonoaudiología,

Pontificia Universidad Católica de Chile, Santiago, Chile.

Conflict of interests: Nonexistent

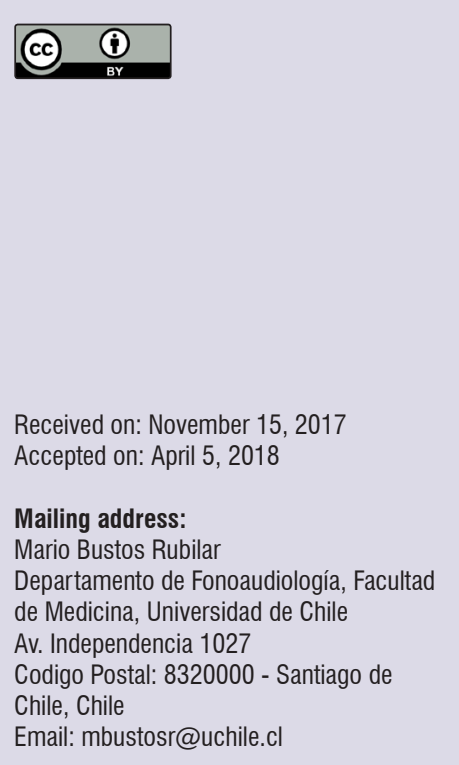

\section{ABSTRACT}

Aim: to characterize the health or education centers that work with deaf children from an early age.

Methods: a survey of those in charge of centers for people with hearing loss $(\mathrm{N}=5)$, special schools for the deaf $(\mathrm{N}=3)$ and hospitals in which therapeutic intervention for people with hearing impairments $(\mathrm{N}=6)$ was carried out in Santiago, Chile in 2014. It consulted the characteristics of the people attended, the intervention method used at each center and information about the professionals making up each team of workers. In addition, information was compiled about whether the institution had inclusion programmes for normal or special education.

Results: the majority of the institutions indicated that they had an oral focus or a variation on this. Only one used the bilingual intercultural model and another indicated that did not use oral models. The results varied concerning access to education and even to professionals, at centers of the same kind.

Conclusion: the majority of the institutions indicated that they worked using the oral intervention methodology, providing fewer options for the early inclusion of bilingual intercultural education or other intervention methodologies.

Keywords: Hearing Loss; Hearing Disorders; Rehabilitation; People with Hearing Impairments 


\section{INTRODUCTION}

In Chile, public policies exist for the treatment of people with pathologies included in the current reform to the health system (AUGE/GES Plan), called "Explicit Healthcare Guarantees"1. In these documents, the actions of the interdisciplinary teams involved are specified. In the case of treatment for people with hearing loss - a condition that affects between 4\%-6\% of our population ${ }^{2}$ - common intervention criteria are established. Early evaluation is recommended for a timely diagnosis ${ }^{3}$ as well as technical implementation for auditory modifications. Although said policies are an important advance, specific actions have not been established concerning education or the community context of each attendee with hearing loss.

Clinical guides suggest using devices such as cochlear implants on those who need them ${ }^{4}$ and propose interventions based on auditory performance ${ }^{5}$. If the child receives early treatment and benefits from auditory assistance, it is recommended using the verbal auditory methodology, an approach that prioritises the auditory channel to development oral language ${ }^{6}$. If the benefit is limited, a less strict oral intervention is suggested, working with other entry canals such as the visual one, in an intervention described as oral auditory $^{7}$. If the device has no benefits, a communication method based on bilingualism is recommended. Such method defends the use of sign language as a first language, as well as insertion into the deaf community and involves developing written or oral language, although in a secondary way ${ }^{8}$. It can be concluded from these suggestions that the main aim and first option is to acquire oral language ${ }^{4}$. This assumes that if the oral channel is not used, communication, cognition and the emotional and social ties of children with hearing loss will be affected.

The belief that sign language does not favour comprehensive development may be explained by the incorrect use of evaluation methods designed for hearing people by hearing impaired children using sign language ${ }^{9}$. The cogitative skills and brain development of people who are hard of hearing are the same as those of people using oral language, with linguistic variables being the only difference ${ }^{10,11}$. Therefore, it is the non-acquisition of functional language during a critical period that produces negative consequences in the cognitive and social development of those who are hard of hearing, irrespective of the type of communication method used ${ }^{12,13}$.
Although approaches that are different from oral methods are considered, the tendency to use oral clinical models ${ }^{14}$ with the Chilean population may have negative repercussions on the communicational development of those who do not achieve good results with this prevailing model. In addition, it must be added that the training of healthcare professionals and the number of centers destined to education with a bilingual approach using sign language are few ${ }^{15}$. This means information is only provided to parents when making a decision about their child's learning or communication method.

In Chile, there are several alternatives for educating children with hearing loss. One is for them to go to normal schools from the age of four. This system offers School Integration Projects (PIE), which aim to incorporate children with hearing loss into normal classrooms ${ }^{16}$. Despite the fact that these programmes have the support of different professionals, no clear policy exists on the use of auditory or visual intervention approaches ${ }^{17}$. On the other hand, special education for children with hearing loss also exists under the Special Education Law and Decree N`86 from 1990. Such a law is limited to some state schools or state schools that receive private donations, which are not regulated as far as the communicative or educational model they use are concerned, except those which currently use bilingual approaches with sign language.

Therefore, this study's aim is to characterise health and educational centers that work with deaf children in Chile's Metropolitan Region. The aim is to discover the characteristics of the patients they attend to, how the professional team is made up and the characteristics of the interventions carried out at each center. The hypothesis is that, when a clinical model predominates, the most common intervention approach is oral, compared to other educational or therapeutic methods, which may also be necessary depending on the children's characteristics.

\section{METHODS}

\section{Design and sample}

This study is descriptive and transversal; a closedformat response survey was carried out on professionals in charge of working with children with hearing loss in public healthcare hospitals, schools (special centers) for deaf children and centers for people with hearing loss in the Metropolitan Region in 2014. Each institution was sent a letter inviting them to take part and 
if they agreed, an informed consent form was signed to this effect. The protocol was approved by the Ethics Committee at the Department of Speech Therapy at the University of Chile's Medical School (0810-2016).

\section{Instrument}

The instrument used consisted of a structured survey of our own creation with a closed format, nine sections and a total of 12 questions in three categories. The first category included information about each center, the second the identification of each location's therapeutic aspects and the third information about the patients who attended each institution.

The questions aimed to: (I) identify the intervention methods used at each center (II) determine the number of minors attended during the year; (III) determine the number of children with and without hearing aids; (IV) determine the diversity of the professionals; (V) establish implementation characteristics and the calibration of these at each center; (VI) determine the number of children abandoning the programme and (VII) establish how children and adolescents with hearing loss are inserted into different educational systems.

\section{Procedures}

The people who initially took part in the survey were authorised to do so by each institution and had access to the required information. This is why the survey was sent out beforehand, together with the letter of invitation. Once a meeting had been scheduled, the survey was carried out face-to-face and lasted on average between 40 minutes and one hour. The survey was carried out by interviewers trained in intervening with children with hearing loss and the functioning of education and health systems.

The information provided by each person surveyed was, in the majority of cases, backed up by a revision of their institutions' data and documents. Given that the methodology used at each centre was sometimes ambiguous or not explicit, each institution's mission and vision was revised, together with an analysis of the answer given by the person in charge at the time the survey was carried out. The aim was to standardise understanding of each centre's therapeutic approach. In some cases, where the response merited quantification, closed options were established according to a Likert-type scale $^{18}$, with the person carrying out the survey explaining each possible option.

\section{Statistical analysis}

To statistically analyse the data obtained, version 12 of the STATA programme (StataCorp, College Station, Texas, USA) and the R programme were used. Given that all the variables were categorical, the descriptive statistics were described using absolute and relative frequencies. When comparing proportions, pairwise comparisons were used, applying Bonferroni's adjustment for multiple contrasts.

As far as the multivariate statistics were concerned, a cluster-type analysis was used. Such a technique allows for groups to be made up according to their similarities in diverse characteristics, with the results shown in a 'dendrogram'19. The advantage of this type of analysis is that the groups are not previously defined by the researcher ${ }^{18}$. The variables were converted to the same scale using proportions and not gross frequencies.

\section{RESULTS}

From the total of 15 Metropolitan Region institutions invited to take part, only one special school for deaf children declined. The professionals included in the sample came from three special education schools for deaf children, five centers for people with hearing loss and six hospitals.

The simple therefore included 14 institutions, which were grouped into centers for people with hearing loss $(\mathrm{N}=5)$, special schools for children with hearing loss and deafness $(\mathrm{N}=3)$ and hospitals that had a special team or unit to evaluate and deal with deaf children and those with hearing loss $(\mathrm{N}=6)$.

At the centers for people with hearing loss, the type of financing, number of children registered and the professionals that worked there all showed variations (Table 1). However, there was certain uniformity in the therapeutic approach, which was mainly oral, with $60 \%$. As far as the type of educational system insertion is concerned (a multiple-choice question), $80 \%$ of the institutions surveyed indicated that their users attended special education schools; $100 \%$ went to normal schools and $60 \%$ indicated that their users were involved in School Integration Projects (PIE). Regarding the type of implementation for youngsters, it should be highlighted that $12 \%$ of those at 'Centre 1' did not use auditory aids (hearing aids and/or implants). In addition, the proportion of use of hearing aids and implants at each centre differed in a statistically significant way. 'Centre 3' had the highest proportion 
of implant use, as opposed to 'Center 1' $(p<0.001)$ and 'Center 2' $(p<0.001)$. 'Center 4 ' had a significantly greater proportion as far as the use of these devices was concerned as compared to 'Center 1' $(p<0.01)$.

Table 1. Intervention Centers for deaf children in Chile's metropolitan region

\begin{tabular}{cccccc}
\hline Variables & Center $\mathbf{1}$ & Center $\mathbf{2}$ & Center $\mathbf{3}$ & Center $\mathbf{4}$ & Center $\mathbf{5}$ \\
\hline Approach & Mixed & Mixed & Oral & Oral & Oral \\
\hline Years functioning & 25 & 8 & 19 & 12 & 20 \\
\hline Number of children & 50 & 30 & 50 & 10 & 5 \\
\hline Type of professional & & & & & \\
Speech therapist & $3(1 \times 16.7)$ & $3(1 \times 10)$ & $2(1 \times 25)$ & $4(1 \times 2.5)$ & $2(1 \times 2.5)$ \\
Special education teacher & $1(1 \times 50)$ & $1(1 \times 30)$ & $1(1 \times 50)$ & $9(1 \times 1.1)$ & $2(1 \times 2.5)$ \\
Psychologist/Psychiatrist & 0 & $2(1 \times 15)$ & $1(1 \times 50)$ & $4(1 \times 2.5)$ & $3(1 \times 1.7)$ \\
Social worker & $2(1 \times 25)$ & $1(1 \times 30)$ & 0 & 0 & 0 \\
Other professionals & $3(1 \times 16.7)$ & $1(1 \times 30)$ & $2(1 \times 25)$ & $4(1 \times 2.5)$ & $4(1 \times 1.3)$ \\
\hline Type of financing & Foundation, self- & State funding. & Private, self- & Private, self- & Private, self- \\
& financ. & financing & financ. & financing \\
\hline Type of implementation & & & & \\
Hearing aid & $38(76 \%)$ & $25(83.3 \%)$ & $15(30 \%)$ & $3(30 \%)$ & $2(40 \%)$ \\
Implant & $6(12 \%)$ & $5(16.6 \%)$ & $35(70 \%)$ & $7(70 \%)$ & $3(60 \%)$ \\
None & $6(12 \%)$ & $0(0 \%)$ & $0(0 \%)$ & $0(0 \%)$ & $0(0 \%)$ \\
\hline method & & & & Yes & No \\
Special education & Yes & Yes & Yes & Yes & No \\
Integration project & No & Yes & Yes & Yes & Yes \\
Normal education & Yes & Yes & Yes & &
\end{tabular}

a The values are expressed in gross numbers as well as in rates (one professional x number of children).

${ }^{b}$ Professional sign language interpreter.

self-financ. $=$ self-financing.

In the schools for deaf children, there was variability among the aspects the study considered (Table 2). From the possible options (oral, mixed and gestural) for the intervention method, none of the options predominated. Differences were observed in the composition of each interdisciplinary team, with members from several disciplines or areas. The number of 'other professionals' from 'School 1' (16 professionals) stood out, as it was the only institution that selected the gestural model as the approach used. As far as the type of implementation was concerned, there was a significant difference between each school concerning not using auditory aids. It stands out that 'School 1' had a greater percentage of non-use $(70.83 \%)$ than 'School 2' and 'School 3' $(p<0.001)$, with this being significantly different $(p<0.001)$. There were significant differences when comparing 'School 2' with 'School 3'. 
Table 2. Schools for deaf children in Chile's metropolitan region

\begin{tabular}{cccc}
\hline Variables & School 1 & School 2 & School 3 \\
\hline Approach & Bilingual Gestural - Written & Mixed & Oral \\
\hline Years functioning & 55 & 45 & 15 \\
\hline Number of children & 120 & 105 & 49 \\
\hline Type of professional & & & $3(1 \times 16.3)$ \\
Speech therapist & $2(1 \times 60)$ & $3(1 \times 35)$ & $11(1 \times 4.5)$ \\
Special education teacher & $15(1 \times 8)$ & $28(1 \times 3.8)$ & $1(1 \times 49)$ \\
Psychologist/Psychiatrist & $2(1 \times 60)$ & $2(1 \times 52.5)$ & 0 \\
Social worker & $1(1 \times 120)$ & $1(1 \times 105)$ & $2(1 \times 24.5)$ \\
Other professionals & $16(1 \times 7.5)$ & $8(1 \times 13.1)$ & Self-financing and state funding \\
\hline Type of financing & Self-financing and state funding & State funding & $31(63.2 \%)$ \\
Type of implementation & & & $18(36.7)$ \\
Hearing aid & $25(20.8 \%)$ & $74(77.7 \%)$ & $0(0 \%)$ \\
Implant & $10(8.3 \%)$ & $17(17.8 \%)$ & \\
None & $85(70.8 \%)$ & $14(14.7 \%)$ & Yes \\
method & & & No \\
Integration project & Yes & Yes & \\
Normal education & No & Yes & \\
\hline Educational system insertion & & & \\
\hline
\end{tabular}

In the group that included hospitals (Table 3), the predominance of the oral approach in the intervention methodology used can be observed. Only one hospital ('Hospital 6') used a mixed approach. The use of hearing aids was present at all the hospitals surveyed. It stands out that 'Hospital 4' had the greatest number of hearing aid users (93.02\%). There were significant implementation differences between this last establishment and 'Hospital 1' $(p<0.001)$, 'Hospital 3' $(p<0.05)$, 'Hospital 5' $(p<0.001)$ and 'Hospital 6' $(p<0.001)$. At the same time, there were differences in the devices used between 'Hospital 1' (with a greater use of implants) and 'Hospital 2' (with a greater use of hearing aids) $(p<0.05)$. There are differences in the number and type of professionals providing attention, while speech therapists were always part of the intervention team. Only 'Hospital 6' had special education teachers and social workers. For the education system insertion method, it could be seen that the majority (80\%) had patients in special schools and $50 \%$ had pupils at normal schools. 
Table 3. Hospitals for the intervention of deaf children in Chile's metropolitan region

\begin{tabular}{ccccccc}
\hline Variables & Hospital 1 & Hospital 2 & Hospital 3 & Hospital 4 & Hospital 5 & Hospital 6 \\
\hline Approach & Oral & Oral & Oral & Oral & Oral & Mixed \\
\hline Years functioning & 11 & 2 & No information & 7 & 6 & 4 \\
\hline Number of children & 25 & 29 & 30 & 43 & 6 & 32 \\
\hline Type of professional & & & & & & \\
Speech therapist & $1(1 \times 25)$ & $2(1 \times 14.5)$ & $1(1 \times 30)$ & $3(1 \times 14.3)$ & $1(1 \times 6)$ & $3(1 \times 10.7)$ \\
Special education teacher & 0 & 0 & 0 & 0 & 0 & $1(1 \times 32)$ \\
Psychologist/Psychiatrist & $1(1 \times 25)$ & $1(1 \times 29)$ & $1(1 \times 30)$ & $2(1 \times 21.5)$ & 0 & $1(1 \times 32)$ \\
Social worker & 0 & 0 & 0 & 0 & 0 & $1(1 \times 32)$ \\
Other professionals & $4(1 \times 6.3)$ & $1(1 \times 29)$ & $1(1 \times 30)$ & $3(1 \times 14.3)$ & 0 & $3(1 \times 10.7)$ \\
\hline Type of financing & State funding & State funding & State funding & State funding & State funding State funding \\
\hline Type of implementation & & & & & & \\
Hearing aid & $5(16.6 \%)$ & $19(65.5 \%)$ & $18(60 \%)$ & $40(93 \%)$ & $0(0 \%)$ & $14(43.7 \%)$ \\
Implant & $20(80 \%)$ & $10(34.4 \%)$ & $12(40 \%)$ & $3(7 \%)$ & $6(100 \%)$ & $18(56.2 \%)$ \\
None & $0(0 \%)$ & $0(0 \%)$ & $0(0 \%)$ & $0(0 \%)$ & $0(0 \%)$ & $0(0 \%)$ \\
\hline method & & & & & \\
Special education & Yes & Yes & Yes & Yes & Yes & No \\
Integration project & Yes & Yes & Yes & Yes & Yes & Yes \\
Normal education & Yes & No & Yes & Yes & No & No \\
\hline Educational system insertion & & &
\end{tabular}

a The values are expressed in gross numbers as well as in rates (one professional $x$ number of children).

${ }^{b}$ Professional sign language interpreter.

\section{Grouping by similarities}

Grouping the centers by type of institution, it can be seen that the oral model predominated (Table 4). Said intervention approach was used in $64.29 \%$ of the total number of institutions. One establishment $(7.4 \%$ of the total) called itself completely bilingual and used a gestural method. Regarding the type of professional, there were variations in how the interdisciplinary teams were made up. Professionals linked to social work and assistance represented $3 \%$ of the total number of professionals working at all the establishments. In the case of special education staff in hospitals, these represented $3.2 \%$ of all the professionals. 
Table 4. Characteristics of the intervention centers, schools and hospitals for deaf children in Chile's metropolitan region

\begin{tabular}{ccccc}
\hline Variables & $\begin{array}{c}\text { Centers } \\
(\mathbf{N}=5)\end{array}$ & Schools (N=3) & Hospitals (N=6) & Total (N=14) \\
\hline Approach & & & & \\
Gestures & $0(0 \%)$ & $1(33 \%)$ & $0(0 \%)$ & $1(7.4 \%)$ \\
Oral & $3(60 \%)$ & $1(33 \%)$ & $5(83 \%)$ & $9(64.29 \%)$ \\
Mixed & $2(40 \%)$ & $1(33 \%)$ & $1(16.67 \%)$ & $4(28.7 \%)$ \\
\hline Number of children & $145(24.8 \%)$ & $274(46.9 \%)$ & $165(28.3 \%)$ & 584 \\
\hline Type of professional & & & & \\
Speech therapist & $14(25.5 \%)$ & $8(8.42 \%)$ & $11(35.5 \%)$ & $33(18.2 \%)$ \\
Special education teacher & $14(25.5 \%)$ & $54(56.8 \%)$ & $1(3.2 \%)$ & $69(38.1 \%)$ \\
Psychologist/Psychiatrist & $10(18.2)$ & $5(5.3 \%)$ & $6(19.4 \%)$ & $21(11.6 \%)$ \\
Social worker & $3(5.5 \%)$ & $2(2.1 \%)$ & $1(3.2 \%)$ & $6(3.3 \%)$ \\
Other professionals & $14(25.5 \%)$ & $26(27.4 \%)$ & $12(38.7 \%)$ & $52(28.7 \%)$ \\
Total per institution & 55 & 144 & 31 & - \\
\hline Type of implementation & $(\mathrm{N}=145)$ & $(\mathrm{N}=274)$ & $(\mathrm{N}=165)$ & $(\mathrm{N}=584)$ \\
Hearing aid & $83(57.2 \%)$ & $130(47.5 \%)$ & $96(58.2 \%)$ & $309(52.9 \%)$ \\
Implant & $56(38.6 \%)$ & $45(16.4 \%)$ & $69(41.8 \%)$ & $170(29.1 \%)$ \\
None & $6(4.14 \%)$ & $99(36.1 \%)$ & $0(0 \%)$ & $105(18.0 \%)$ \\
\hline Educational system insertion & & & & \\
model (multiple choice & & & & - \\
answer) & & $0(0 \%)$ & $5(83 \%)$ & - \\
Special education & $4(80 \%)$ & $3(100 \%)$ & $6(100 \%)$ & - \\
Integration project & $3(60 \%)$ & $1(33 \%)$ & $3(50 \%)$ & \\
Normal education & $5(100 \%)$ & & & \\
\hline
\end{tabular}

In the dendrogram, the grouping of the institutions can be visualised according to their degrees of similarity in all the variables considered (Figure 1). A group of nine entities can be seen, which form a large cluster, mainly including those using oral intervention models. The group was made up of all the hospitals and centers, with the exception of 'Centre 1' and 'Centre 5', with the latter being an entity that distanced itself from the main group. In a second cluster of institutions, the left hand side of the dendrogram was made up of all the schools, with entities using other intervention models positioned to the extreme left. 


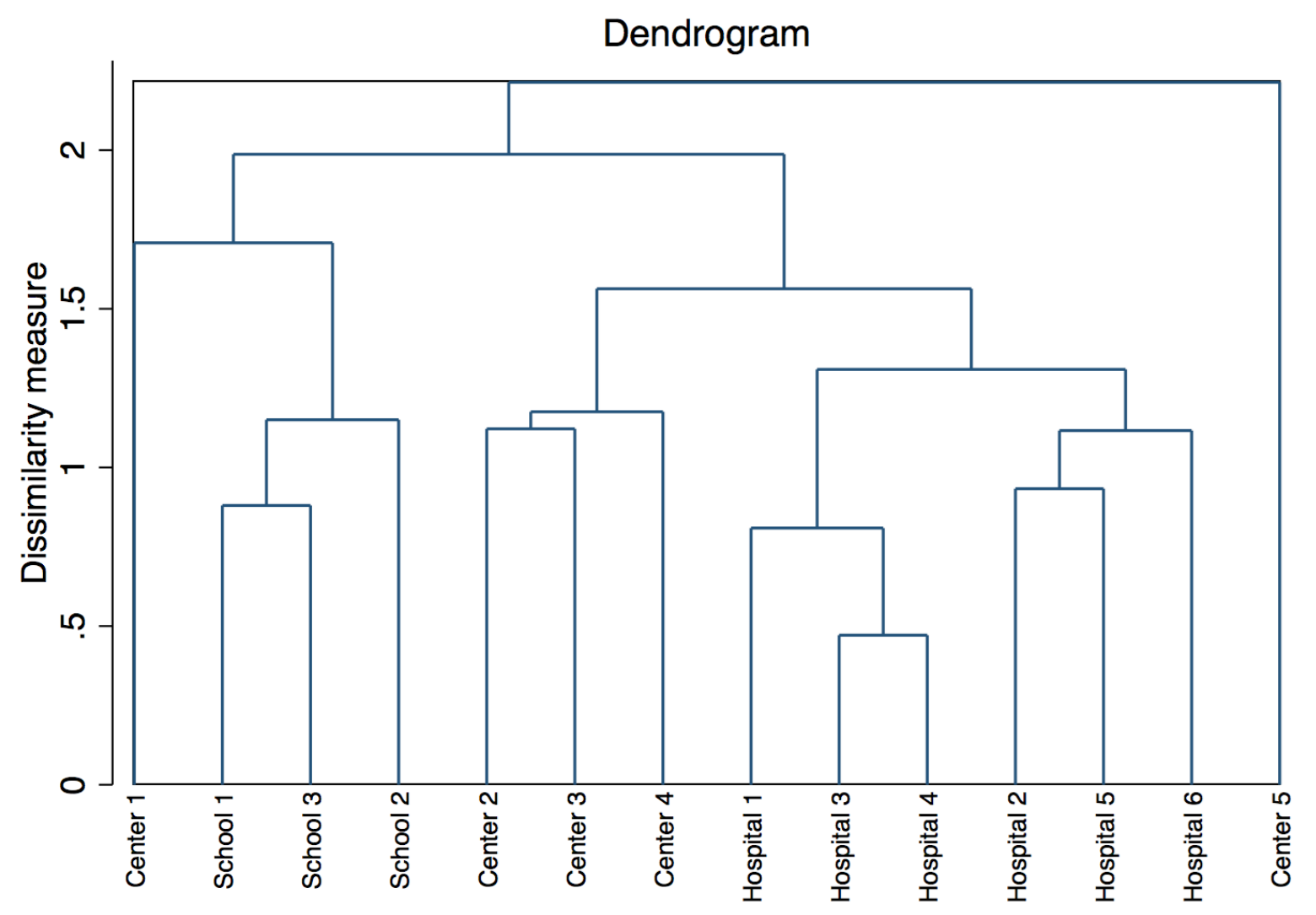

Figure 1. Dendrogram of similarities between the participating institutions

There were variations in how the three types of establishment were grouped and even distance within groups made up of the same type. In the case of the centers for people with hearing loss, 'Center 1' was isolated from the schools, while 'Center 2', 'Center 3' and 'Center 4' were closer. Finally, the hospitals made up a group on their own and there was the possibility of sub-dividing them into two groups.

\section{DISCUSSION}

The aim of this study was to characterise the health and education centers that work with deaf children in Chile's Metropolitan Region. The hypothesis was that the use of an oral therapeutic approach predominated. The results of this study prove the aforementioned hypothesis, with it being observed that the oral method is used at $60 \%$ of the sample's institutions. In addition, there was certain homogeneity among the private centers and hospitals that carry out interventions using the oral method. The choice of this approach could be explained by the child's family hearing context, since parents and family members do not usually suffer hearing loss ${ }^{20}$.
To this must be added the clinical orientation of current public health policies (GES), which emphasise a health concept based on normalising deficits ${ }^{21}$, leaving no room for other intervention models. This is a problem for those who do not obtain favourable results with oral intervention during the expected critical periods or in cases where auditory implementation does not provide functional hearing. This is relevant considering that the average age of hearing loss detection in Chile is at three years old ${ }^{22}$, something that could be considered as late for successful auditory and language intervention. This could be related to the low adherence to using devices observed in the sample. In children with hearing loss, both the type of loss and timely implementation have a direct influence on the use of auditory aids ${ }^{23,24}$. On the other hand, parents should receive information about each existing intervention approach in a timely fashion. In summary, early intervention in auditory problems is important, irrespective of the therapeutic method (oral, gestural or mixed) used.

In this study, only one school indicated that they provided bilingual education with sign language. Said establishment was grouped together with the other schools, far from the other centers in the dendrogram. 
The lack of a bilingual offer could be due to the stigmatisation associated with the use of sign language ${ }^{25}$ and people not choosing the method due to a lack of knowledge of the learning needs of people with hearing loss.

Regarding integration into the education system, all the users were inserted into some type of establishment, with variability between normal or formal education and School Integration Projects (PIE). The degree of interrelation between health and education institutions is unknown, since no regulations exist on their working together. An important task for educational centers is to get directly involved with health teams. The early experiences of these users should not only be in a health context, but also a social one, integrating all the areas involved in attending to this group. This can be seen in how things work in countries such as the United Kingdom, United States and Canada, where there is a greater interdisciplinary focus when attending to and encouraging the role of parents as responsible actors. In the case of Canada, although the doctor provides the diagnosis initial, it is a social worker who notifies and offers intervention options to the family, including auditory implementation and verbal auditory intervention; integration into the deaf community by learning sign language, together with bilingual education and lastly the combined method, which provides the opportunity to use auditory devices, receive auditory therapy and integrate into the deaf community ${ }^{26}$.

When observing the reality of Latin America, there are common denominators in this same environment that limit intervention using different therapeutic methods for people with hearing loss. The fact that attending to them is a low priority, that there is hardly any advanced human capital in the area, the spread of the population over very extensive geographical areas and the high cost of intervention in Latin America may all contribute to decreasing the number of resources available to attend to this group ${ }^{27}$.

Another important point that was observed concerned the information provided by the hospitals surveyed, with only one employing professionals from the area of education. This could mean a reduction in the number of users attended at places without trained professionals in the area of education, faced with the need for earlier access to information and learning that deaf children have when comparing them to hearing ones $^{28}$. The participation of these professionals in early healthcare attention, together with the participation of social workers, could complement the work of and information provided by healthcare personnel to the parents of diagnosed children.

Regarding the dendrogram's grouping according to the similarities observed, the uniformity between schools and hospitals stands out, but not that of centers for people with hearing loss. This may lead to these centers working more independently and with greater autonomy from state policies. It is therefore relevant that these policies be analysed, with the expectation being that there is a greater interrelation between the institutions that provide attention for people with auditory impairments. According to this, it is important that educational bodies in Chile get involved with healthcare teams early on, building a relationship and working together to the benefit of the users.

\section{Limitations of the study}

One of the study's limitations is that the sample was pre-arranged. No register of all the state-run centers that deal with people with auditory impairments exists. However, the sample obtained is believed to be sufficiently large so as to be able to portray our country's reality. As far as the information collected is concerned, it is difficult to compare the numbers of professionals to the number of children, given that there was no information available about the number of hours the professionals worked at each center. For example, institutions could have a single therapist working 44 hours, two for 22 hours each or more professionals for fewer hours.

Another possible limitation is that it was not possible to directly extrapolate the study's results to other countries in the region. However, comprehensive intervention for people with auditory impairments is still scarce in other countries in the region, due to the fact that this is considered a low priority compared to other health conditions ${ }^{27}$, which could replicate the reality described in other zones in the region. In our opinion, research on this subject is scarce in South America, with more being needed on what is an important topic for professionals dealing with the rehabilitation of people with auditory impairments.

\section{CONCLUSIONS}

The results of this study indicate the predominance of the oral approach as an intervention method for people with hearing loss. In addition, there was greater homogeneity regarding the type of intervention, with few institutions offering bilingual education with sign language or another type of education. Said 
predominance could be explained by the parents' choices and the influence of the clinical model, which emphasises helping deaf people speak. At the same time, this could restrict early access to education based on sign language for those who need it and therefore delay the development of language and other cognitive skills.

\section{ACKNOWLEDGEMENTS}

We would like to thank all the institutions that freely and voluntarily took part in this research. The authors would also like to thank students Ariel Ballesteros, Paulina Riveros, Carolina Vergara and Camila Videla from the Department of Speech Therapy at the University of Chile for their help with carrying out the project.

\section{REFERENCES}

1. Ministerio de Salud. Decreto №3 Aprueba garantías explícitas en salud del régimen general de gariantías en salud. 2016.

2. Organizacion Mundial de la Salud. Evaluación multipaís de la capacidad nacional de prestación de atención audiológica. 2014.

3. Schonhaut L, Farfán C, Neuvonen R, Vacarisas P. Problemas auditivos en preescolares, según estudio audiológico y percepción de educadores: Región Metropolitana. Rev Chil Pediatr. 2014;77(3):247-53.

4. Ministerio de Salud. Guía Clinica AUGE hipoacusia sensorioneural bilateral del prematuro. 2009.

5. Miniserio de Salud. Guía Clínica GES Tratamiento de hipoacusia moderada para menores de 2 años. 2013.

6. De Maggi MM. Terapia Auditivo Verbal. Enseñar a escuchar para aprender hablar. Auditio. 2004;2(3):64-72.

7. Quique Y, FA MT. Métodos unisensoriales para la rehabilitación de la persona con implante coclear y métodos musicoterapéuticos como nueva herramienta de intervención. Rev. Otorrinolaringol. Cir. Cabeza Cuello. 2013;73(1):94-108.

8. Johnson RE, Liddell SK, Erting CJ. Unlocking the curriculum: principles for achieving access in deaf education. Working Paper 89-3: Gallaudet Research Inst, Washington DC; 1989.

9. Marschark M. Intellectual functioning of deaf adults and children: answers and questions. Eur $\mathrm{J}$ Cogn Psychol. 2006;18(1):70-89.
10. Courtin C. A Critical period for the acquisition of the theory of mind? Clues from homesigners. In: Mathur G, Napoli DJ (Eds). Deaf around the world: the impact of language. Oxford, U.K.: Oxford University Press; 2010.p.185-7.

11. Courtin $C$. The impact of sign language on the cognitive development of deaf children: The case of theories of mind. J Deaf Stud Deaf Educ. 2000;5(3):266-76.

12. Humphries T, Kushalnagar P, Mathur G, Napoli DJ, Padden C, Rathmann C. Ensuring language acquisition for deaf children: What linguists can do. Language. 2014;90(2):e31-e52.

13. Mathur G, Napoli DJ. Deaf around the world: The impact of language. Oxford, UK. Oxford University Press; 2010.

14. Herrera V. Estudio de la población sorda en Chile: evolución histórica y perspectivas lingüísticas, educativas y sociales. Revista Latinoamericana de Educación Inclusiva. 2010;4(1):211-26.

15. Lissi MR, Svartholm K, González M. El enfoque bilingüe en la educación de sordos: sus implicancias para la enseñanza y aprendizaje de la lengua escrita. Estudios pedagógicos (Valdivia). 2012;38(2):299-320.

16. Tenorio Eitel $S$. La integración escolar en chile: perspectiva de los docentes sobre su implementación. REICE. Revista Iberoamericana sobre Calidad, Eficacia y Cambio en Educación. 2005;3(1):825-6.

17. López V, Julio C, Pérez MV. Barreras culturales para la inclusión: políticas y prácticas de integración en Chile. Revista de Educación. 2014;363(180):256-81.

18. Albaum G. The Likert Scale revisited: an alternate version. J Mark Res Soc. 1997;39(2):331-2.

19. Tufféry S. Data mining and statistics for decision making. 2nd edn John Wiley \& Sons; 2011.

20. Smith RJ, Bale JF, White KR. Sensorineural hearing loss in children. The Lancet. 2005;365(9462):879-90.

21. García V, Hoover J, Gil Obando LM. La discapacidad, una mirada desde la teoría de sistemas y el modelo biopsicosocial. Revista Hacia la Promoción de la Salud. 2007;12(1):51-61.

22. Cardemil F. Aspectos éticos en el tamizaje de hipoacusia neonatal en Chile. Rev. Otorrinolaringol. Cir. Cabeza Cuello. 2012;72(3):249-60.

23. Gustafson S, Davis H, Hornsby B, Bess F. Factors influencing hearing aid use in the classroom: a pilot study. Am J Audiol. 2015;24(4):563-8 
24. Walker E, Spratford M, Moeller M, Oleson J, Ou H, Roush $\mathrm{P}$ et al. Predictors of hearing aid use time in children with mild-to-severe hearing loss. Lang Speech Hear Serv Sch. 2013;44(1):73-88.

25. Cuevas H. El gobierno de los sordos: el dispositivo educacional. Revista de ciencia política (Santiago). 2013;33(3):693-713.

26. Weisel A. Issues unresolved: new perspectives on language and deaf education. Washington DC. Gallaudet University Press; 1998.

27. Madriz JJ. Hearing impairment in latin america: an inventory of limited options and resources. Audiology. 2000;39(4):212-20.

28. Moeller MP. Early intervention and language development in children who are deaf and hard of hearing. Pediatrics. 2000;106(3):E43. 